\title{
Intra-partum fever and cerebral palsy in Khartoum, Sudan
}

\author{
Hala Abdullahi, Mohamed Satti, Duria A Rayis, Abdulmutalab M Imam and Ishag Adam*
}

\begin{abstract}
Background: Cerebral palsy (CP) is a major cause of childhood disability. There are various maternal and neonatal predictors associated with the development of $\mathrm{CP}$, and they are variable across different populations. This case-control study was designed to investigate maternal and neonatal predictors of CP at Khartoum pediatric neurology clinics. Data (maternal sociodemographic characteristics and neonatal expected predictors) were collected from mothers of children with CP and healthy controls using questionnaires.

Results: One hundred and eleven cases of CP and 222 controls were included. Spastic CP was the most common type (69.4\%). In logistic regression, maternal age, parity, birth weight, and sex were not associated with CP. However, maternal fever $(\mathrm{OR}=8.4, \mathrm{Cl}=2.3-30.5 ; \mathrm{P}=0.001)$, previous neonatal death $(\mathrm{OR}=5.4, \mathrm{Cl}=1.8-16.2$; $\mathrm{P}=0.003)$, and poor sucking $(\mathrm{OR}=30.5, \mathrm{Cl}=10.0-93.1 ; \mathrm{P}<0.001)$ were predictors of $\mathrm{CP}$.

Conclusions: Fever during labor is a significant risk factor for developing $\mathrm{CP}$ in children. Further efforts are required for labor management to prevent CP in this setting.
\end{abstract}

Keywords: Cerebral palsy, Labor, Pregnancy, Sudan

\section{Background}

Cerebral palsy $(\mathrm{CP})$ is a group of permanent disorders of development of movement and posture, causing activity limitation, and it is attributed to non-progressive disturbances that occur in the developing fetal or infant brain [1]. CP is the most common physical disability in children, affecting 1-2 per 1000 live births [2-5].

The exact etiology of $\mathrm{CP}$ is not yet well understood, and brain lesions are thought to be associated with perinatal events of varying causes. Several predictors for the development of $\mathrm{CP}$ have been identified in various settings, such as maternal age, pre-eclampsia, chorioamnionitis, small for gestational age, multiple births, assisted reproduction, a relative with $\mathrm{CP}$, breech position, bleeding at any time in pregnancy, male sex, and multiple miscarriages [4,6-15]. These factors are variable among different populations.

The predictors of CP need to be determined to generate basic data for producing interventional measures to reduce the risk of $\mathrm{CP}$. While there are a lot of published data on the epidemiology of $\mathrm{CP}$ in other countries, there are no published studies regarding the risk factors for

\footnotetext{
* Correspondence: ishagadam@hotmail.com

Department of Obstetrics and Gynecology, University of Khartoum, Khartoum, Sudan
}

$\mathrm{CP}$ in Sudan. In this case-control study, we aimed to investigate the predictors of $\mathrm{CP}$ in Khartoum to add to previous knowledge on neonatal morbidity and mortality in this country $[16,17]$.

\section{Methods}

A case-control study was conducted at the pediatric neurology clinic in Khartoum, Sudan, between January and June 2012. A sample size of 110 subjects was calculated based on a two-sided hypothesis test using Epi Info with $80 \%$ power to detect a difference of $5 \%$ at $\alpha=0.05$ and a confidence interval of $95 \%$, and $10 \%$ of non-responders were expected. The mothers of children who had already been diagnosed with $\mathrm{CP}$ (based on the medical history, a clinical examination, and imaging of the brain) and who attended follow-up were interviewed using a pretested questionnaire. Cases with $\mathrm{CP}$ were classified into three major categories; spastic, dyskinetic, and ataxic subtypes.

Two controls for each case were selected from the hospital, matched for time and place of birth as much as possible after exclusion of major congenital anomalies. After obtaining informed consent, pretested questionnaires were applied for each mother/guardian to gather maternal sociodemographic characteristics, and information on labor 
and perinatal and neonatal events that were expected to be predictors for CP (age, parity, antepartum hemorrhage, intra-partum fever, mode of delivery, gestational age, birth weight, and admission to the nursery).

\section{Statistical analysis}

Data were analyzed using SPSS (Social Package for Scientific Statistic) version 17.0. Means and proportions were compared between the cases and controls using the $t$-test and $X^{2}$ test as appropriate. Univariate and multivariate analyses were performed with $\mathrm{CP}$ as the dependent variable, and maternal and neonatal factors as independent variables. $\mathrm{P}<0.05$ was considered statistically significant.

\section{Ethics}

Ethical approval was obtained from the Sudan Medical Specialization Board.

\section{Results}

There were 111 cases of CP and 222 controls. Different types of CP were observed as follows: spastic (77; 69.4\%), dyskinetic; $(24 ; 21.6 \%$ ), ataxic (seven; 6.3\%), and mixed (three; $2.7 \%)$. The age ranged from 1-11 years, with a mean (SD) of 4.1 (2.9) years. The mean maternal age (31.5 [7.5] vs. 32.5 [6.8] years, $\mathrm{P}=0.256)$ and paternal age $(40.8$ [9.2] vs. 42.0 [8.9] years, $\mathrm{P}=0.263$ ) were not significantly different between the CP group and controls. The mean birth weight was slightly lower (not significant) in the CP group compared with controls (2970.2 [644.4] vs. 3019.0 [651.5] g, $\mathrm{P}=0.534)$.

While there was no significant difference in most of the sociodemographic characteristics between the CP group and controls, significantly more mothers in the CP group had a history of neonatal death (16 [14.4\%] vs. 9 [4.1\%], $\mathrm{P}=0.001)$, had previous newborns with $\mathrm{CP}(7[6.3 \%]$ vs. 1 $[0.5], \mathrm{P}=0.002$ ), and had fever during delivery of the index baby $(22$ [19.8\%] vs. 4 [1.8\%], P < 0.001) compared with the controls. Significantly more children in the CP group presented in breech (15 [13.5\%] vs 14 [6.3\%] $\mathrm{P}=0.03]$, had poor sucking (53 [47.7\%] vs 6 [2.7\%], $\mathrm{P}<0.001)$, and were admitted to the neonatal care unit earlier in their life (23 [20.7\%] vs 7 [3.2\%], $\mathrm{P}<0.001$ ) (Table 1 ).

Parity, a history of miscarriage, antepartum hemorrhage, gestational age, induction of labor, and mode of delivery were not significantly associated with $\mathrm{CP}$. Breech presentation $(\mathrm{OR}=2.3, \mathrm{CI}=2.1-5.0 ; \mathrm{P}=0.031)$ and a previous child with $\mathrm{CP}(\mathrm{OR}=14.9, \mathrm{CI}=1.8-122.4 ; \mathrm{P}=0.012)$ were significant risk factors in univariate analysis but not in multivariate analysis (Table 2).

In multivariate analysis, maternal fever $(\mathrm{OR}=8.4, \mathrm{CI}=$ 2.3-30.5; $\mathrm{P}=0.001)$, previous neonatal death $(\mathrm{OR}=5.4$, $\mathrm{CI}=1.8-16.2 ; \mathrm{P}=0.003)$, and poor sucking $(\mathrm{OR}=30.5$, $\mathrm{CI}=10.0-93.1 ; \mathrm{P}<0.001)$ were predictors for CP (Table 2).

\section{Discussion}

The main findings of this study were that maternal fever, previous neonatal death, and poor sucking were significant predictors of CP in Khartoum, whereas maternal age, parity, birth weight, and sex were not associated with CP. In this study, only $70 \%$ of these children had spastic CP. Previous studies in other developing countries, such as India [18] and Egypt [5], showed that spasticity is the most common type of CP. Paternal and maternal age have been reported to be associated with an increasing risk of $\mathrm{CP}$ in other studies [12,19].

Gestational age and birth weight were not associated with $\mathrm{CP}$ in the current study. More than half of all children with CP are not preterm deliveries [20-22]. However, prematurity and low birth weight have been found to be associated with $\mathrm{CP}$ in other populations $[4,12]$. Recall and selection bias might be responsible for masking the true effects of birth weight and gestational age in the current study. Generally, the actual birth weight and gestational age are only reliable if a prospective or longitudinal study is conducted, which is difficult in a setting such as Khartoum.

A history of having a child with $\mathrm{CP}$ was associated with $\mathrm{CP}$ in univariate but not in multivariate analysis in our study. Previous poor obstetric history, such as miscarriage,

\section{Table 1 Comparison of sociodemographic characteristics of CP cases and controls}

\begin{tabular}{llll}
\hline Variables & $\begin{array}{l}\text { Cases with cerebral } \\
\text { palsy }(\mathbf{n = 1 1 1})\end{array}$ & $\begin{array}{l}\text { Healthy controls } \\
(\mathbf{n}=\mathbf{2 2 2})\end{array}$ & $\mathbf{P}$ \\
\hline $\begin{array}{l}\text { Previous maternal } \\
\text { history of }\end{array}$ & & & \\
Miscarriage & $23(33.0)$ & $43(19.4)$ & 0.772 \\
Preterm delivery & $3(2.7)$ & $4(1.8)$ & 0.690 \\
Neonatal death & $16(14.4)$ & $9(4.1)$ & 0.001 \\
$\begin{array}{l}\text { Baby with cerebral } \\
\text { palsy }\end{array}$ & $7(6.3)$ & $1(0.5)$ & 0.002 \\
Cesarean delivery & $7(6.3)$ & $22(9.9)$ & 0.309 \\
Variables related to pregnancy being questioned & \\
Assisted conception & $3(2.7)$ & $6(2.7)$ & 1.000 \\
Antepartum & $7(6.3)$ & $6(2.7)$ & 0.135 \\
hemorrhage & & & \\
Multiple conception & $6(5.4)$ & $8(3.6)$ & 0.563 \\
Male gender & $59(53.2)$ & $131(59.0)$ & 0.348 \\
Induction of labor & $5(4.5)$ & $11(5.0)$ & 1.000 \\
Fever during labor & $22(19.8)$ & $4(1.8)$ & $<0.001$ \\
Vaginal delivery & $99(89.2)$ & $183(82.4)$ & 0.824 \\
Cesarean delivery & $12(10.8)$ & $39(17.6)$ & 0.824 \\
Breech presentation & $15(13.5)$ & $14(6.3)$ & 0.03 \\
Admission to the & $23(20.7)$ & $7(3.2)$ & $<0.001$ \\
neonatal care unit & & $6(2.7)$ & $<0.001$ \\
Poor sucking & $53(47.7)$ & & \\
\hline
\end{tabular}


Table 2 Univariate and multivariate analyses for possible predictors of cerebral palsy among children in Khartoum, Sudan

\begin{tabular}{|c|c|c|c|c|c|c|}
\hline \multirow[t]{2}{*}{ Variables } & \multicolumn{3}{|c|}{ Univariate analysis } & \multicolumn{3}{|c|}{ Multivariate analysis } \\
\hline & OR & $95 \% \mathrm{Cl}$ & $\mathbf{P}$ & OR & $95 \% \mathrm{Cl}$ & $\mathbf{P}$ \\
\hline Maternal age & 1.0 & $1.0-1.1$ & 0.255 & 1.0 & $0.9-1.0$ & 0.517 \\
\hline Parity & 1.1 & $1.0-1.2$ & 0.093 & 1.1 & $0.9-1.4$ & 0.211 \\
\hline History of miscarriage & 1.1 & $0.6-1.9$ & 0.771 & 1.0 & $0.4-2.3$ & 0.991 \\
\hline Antepartum hemorrhage & 2.4 & $0.8-7.4$ & 0.12 & 1.9 & $0.4-8.4$ & 0.397 \\
\hline Previous baby with cerebral Palsy & 14.9 & $1.8-122.4$ & 0.012 & 8.2 & $0.7-92.4$ & 0.088 \\
\hline Previous neonatal death & 4.0 & $1.7-9.3$ & 0.001 & 5.4 & $1.8-16.2$ & $0.003^{*}$ \\
\hline Previous cesarean delivery & 0.6 & $0.3-1.5$ & 0.276 & 0.2 & $0.04-1.0$ & 0.058 \\
\hline Male gender & 0.8 & $0.5-1.2$ & 0.303 & 0.8 & $0.4-1.5$ & 0.441 \\
\hline Induction of labor & 0.9 & $0.3-2.7$ & 0.856 & 1.0 & $0.2-4.4$ & 0.987 \\
\hline Fever during labor & 31.5 & $4.5-40.2$ & $<0.001$ & 8.4 & $2.3-30.5$ & $0.001^{*}$ \\
\hline Cesarean delivery & 1.1 & $0.8-1.5$ & 0.524 & 0.8 & $0.5-1.4$ & 0.485 \\
\hline Breech presentation & 2.3 & $1.1-5.0$ & 0.031 & 0.6 & $0.2-1.9$ & 0.374 \\
\hline Birth weight & 1.1 & $0.8-1.6$ & 0.535 & 0.9 & $0.6-1.4$ & 0.660 \\
\hline Gestational age & 1.1 & $1.0-1.2$ & 0.08 & 0.9 & $0.8-1.1$ & 0.531 \\
\hline Admission to the neonatal unit & 8.0 & $3.3-19.4$ & $<0.001$ & 1.2 & $0.3-5.4$ & 0.793 \\
\hline Poor sucking & 32.9 & $13.5-80.3$ & $<0.001$ & 30.5 & $10.0-93.1$ & $<0.001^{*}$ \\
\hline
\end{tabular}

*Adjusted for confounders.

intrauterine fetal death, neonatal death, or a previous child with disability, is associated with an increasing risk of CP $[23,24]$. Having a child with CP appears to increase the risk in subsequent children, possibly because of genetic predisposition [25-27]. Early feeding difficulties manifesting as poor sucking abilities was a significant predictor for the development of CP in our study, as well as in other studies [28,29].

In the current study, mothers with a history of fever during labor had a nine times greater risk of having newborns with CP. This may reflect suboptimal antenatal care or suboptimal management of labor. We have recently observed that obstructed labor constitutes a major threat to the mother and fetus in Eastern Sudan [30]. Furthermore, we have recently found that infection is the leading cause for admission to the nursery for newborns born in hospital [17]. Unfortunately, even in the capital, Khartoum, suboptimal care of labor and its management are responsible for high perinatal death, which is 51 per 1000 births [31]. Therefore, the current study supports several previous studies showing that maternal infection at the time of delivery is an important risk factor for CP $[4,7,8,10,14,15]$.

One of the limitations of this study is that the delivery data were collected from mothers many years after the event. Therefore, inherent risks of recall bias can be expected. This is especially relevant when women were asked about fever in labor, which can be a subjective symptom, and we did not refer to the delivery notes. However, this question was explained as a high temperature being confirmed by the attending treating doctor or requiring intervention to treat it. The study group was a sample from pediatric neurology clinics over a 6-month period. This may have skewed the sample of children with $\mathrm{CP}$ because they do not represent all patients in the community. Less severe cases may not have been well represented and not all adhered to follow-up because of various barriers, including limited transport and financial resources. Using hospital-based controls is convenient for data collection, but they are not ideal because they may have other confounders that made them present to the hospital.

\section{Conclusions}

Mothers having previous newborns with CP, poor sucking, and fever during labor are predictors for developing CP in children. There should be further efforts antenatally and during labor to introduce measures and management options for reducing CP in this setting.

Competing interests

The authors declare that they have no competing interests.

Authors' contributions

$H A, M S$, and IA designed the study. DAR and Al conducted the clinical part of the study. DAR and IA performed statistical analysis. All the authors read and approved the final version.

\section{Acknowledgements}

The authors are grateful to the women who participated in the study and to all the medical and nursing staff at the pediatric neurology clinics. 
Received: 27 December 2012 Accepted: 23 April 2013

Published: 24 April 2013

\section{References}

1. Rosenbaum P, Paneth N, Leviton A, Goldstein M, Bax M, Damiano D, Dan B, Jacobsson B: A report: the definition and classification of cerebral palsy April 2006. Dev Med Child Neurol Suppl 2007, 109:8-14.

2. Winter S, Autry A, Boyle C, Yeargin-Allsopp M: Trends in the prevalence of cerebral palsy in a population-based study. Pediatrics 2002, 110:1220-1225.

3. Paneth $\mathrm{N}$, Hong $\mathrm{T}$, Korzeniewski $\mathrm{S}$ : The descriptive epidemiology of cerebral palsy. Clin Perinatol 2006, 33(2):251

4. O'Callaghan ME, MacLennan AH, Gibson CS, McMichael GL, Haan EA, Broadbent JL, Goldwater PN, Dekker GA, Australian Collaborative Cerebral Palsy Research Group: Epidemiologic associations with cerebral palsy. Obstet Gynecol 2011, 118(3):576-582.

5. El-Tallawy HN, Farghaly WA, Shehata GA: Epidemiology of cerebral palsy in El-Kharga District-New Valley (Egypt). Brain Dev 2011, 33:406-411.

6. Collins M, Paneth N: Pre-eclampsia and cerebral palsy: are they related? Dev Med Child Neurol 1988, 40:207-211.

7. Wu YW, Colford JM: Chorioamnionitis as a risk factor for cerebral palsy a meta-analysis. JAMA 2000, 284(11):1417-1424.

8. Wu YW, Escobar GJ, Grether JK, Croen LA, Greene JD, Newman TB: Chorioamnionitis and cerebral palsy in term and near-term infants. JAMA 2003, 290(20):2677-2684.

9. Greenwood C, Yudkin P, Sellers S, Impey L, Doyle P: Why is there a modifying effect of gestational age on risk factors for cerebral palsy? Arch Dis Child Fetal Neonatal Ed 2005, 90(2):141-146.

10. Neufeld MD, Frigon C, Graham AS, Mueller BA: Maternal infection and risk of cerebral palsy in term and preterm infants. J Perinato/ 2005, 25:108-113.

11. Klemetti R, Sevon T, Gissler M, Hemminki E: Health of children born as a result of in vitro fertilization. Pediatrics 2006, 118:1819-1827.

12. Wu YW, Croen LA, Shah SJ, Newman TB, Najjar DV: Cerebral palsy in a term population: risk factors and neuroimaging findings. Pediatrics 2006, 118:690

13. Hvidtjorn D, Grove J, Schendel D, Svaerke C, Schieve LA, Uldall P, Ernst E, Jacobsson B, Thorsen P: Multiplicity and early gestational age contribute to an increased risk of cerebral palsy from assisted conception: a population-based cohort study. Hum Reprod 2010, 25:2115-2123.

14. Bessières $B$, Bernard $P$ : Chorio-amnionitis: clinical and biological aspects-medicolegal implications. Gynecol Obstet Fertil 2011, 39(6):383-387.

15. Horvath B, Grasselly M, Bodecs T, Boncz I, Bodis J: Histological chorioamnionitis is associated with cerebral palsy in preterm neonates. Eur J Obstet Gynecol Reprod Biol 2012, 163(2):160-164

16. Elhassan EM, Hassan AA, Mirghani OA, Adam I: Morbidity and mortality pattern of neonates admitted into nursery unit in Wad medani hospital, Sudan. Sudan J Med Science 2010, 5(1):1316.

17. Ali AA, Rayis DA, Abdallah TM, Elbashir Ml, Adam I: Severe anaemia is associated with a higher risk for preeclampsia and poor perinatal outcomes in kassala hospital, eastern Sudan. BMC Research Notes 2011, 4:311.

18. Srivastava VK, Laisram N, Srivastava RK: Cerebral palsy. Indian Pediatr 1992, 29(8):993-996.

19. Fletcher NA, Foley J: Parental age, genetic mutation, and cerebral palsy. J Med Genet 1993, 30(1):44-46.

20. Hagberg B, Hagberg G, Beckung E, Uvebrant P: Changing panorama of cerebral palsy in Sweden. VIII. Prevalence and origin in the birth year period 1991-94. Acta Paediatr 2001, 90:271-277.

21. Grether JK, Cummins SK, Nelson KB: The California cerebral palsy project. Paediatr Perinat Epidemiol 1992, 6:339-351.

22. Thorngren-Jerneck $\mathrm{K}$, Herbst A: Perinatal factors associated with cerebral palsy in children born in Sweden. Obstet Gynecol 2006, 108(6):1499-1505.

23. Nelson KB, Ellenberg $\mathrm{JH}$ : Antecedents of cerebral palsy. Multivariate analysis of risk factors. N Engl J Med 1986, 315:81-86.

24. Hemminki K, Li X, Sundquist K, Sundquist J: High familial risks for cerebral palsy implicate partial heritable aetiology. Paediatr Perinat Epidemiol 2007, 21(3):235-241

25. Menkes JH, Flores-Sarnat L: Cerebral palsy due to chromosomal anomalies and continuous gene syndromes. Clin Perinatol 2006, 33(2):481-501.

26. Gibson CS, MacLennan AH, Goldwater PN, Haan EA, Priest K, Dekker GA, South Australian Cerebral Palsy Research Group: The association between inherited cytokine polymorphisms and cerebral palsy. AJOG 2006, 194(3):674. e1-11.
27. Schaefer GB: Genetics considerations in cerebral palsy. Semin Pediatr Neurol 2008, 15(1):21-26.

28. Motion S, Northstone K, Emond A, Stucke S, Golding J: Early feeding problems in children with cerebral palsy: weight and neurodevelopmental outcomes. Dev Med Child Neurol 2002, 44(1):40-43.

29. Wilson EM, Hustad KC: Early feeding abilities in children with cerebral palsy: a parental report study. J Med Speech Lang Pathol. 2009; MARCH: nihpa57357.

30. Ali AA, Adam I: Maternal and perinatal outcomes of obstructed labour in kassala hospital Sudan. J Obstet Gynaecol 2010, 30(4):376-7.

31. Hassan AA, Abubaker MS, Radi EA, Adam I: Education, prenatal care, and poor perinatal outcome in Khartoum Sudan. Int J Gynaecol Obstet 2009, 105(1):66-7.

doi:10.1186/1756-0500-6-163

Cite this article as: Abdullahi et al:: Intra-partum fever and cerebral palsy in Khartoum, Sudan. BMC Research Notes 2013 6:163.

\section{Submit your next manuscript to BioMed Central and take full advantage of:}

- Convenient online submission

- Thorough peer review

- No space constraints or color figure charges

- Immediate publication on acceptance

- Inclusion in PubMed, CAS, Scopus and Google Scholar

- Research which is freely available for redistribution

Submit your manuscript at www.biomedcentral.com/submit
C Biomed Central 